\title{
(DES)LUSOFONIAS \\ E (DES)ENSINOS: \\ POR OUTRAS \\ POLÍTICAS \\ LINGUÍSTICAS
}

(DIS) LUSOFONÍAS Y (DES) ENSEÑANZAS: PARA OTRAS POLÍTICAS LINGÜÍSTICAS

(DIS)LUSOPHONIES AND (UN)TEACHINGS: FOR OTHER LANGUAGE POLICIES

Alexandre Cohn da Silveira*

Universidade da Integração internacional da Lusofonia Afro-brasileira

Charlott Eloize Leviski**

Universidade Estadual de Ponta Grossa

Sabrina Garcia Rodrigues Balsalobre***

Universidade da Integração internacional da Lusofonia Afro-brasileira

RESUMO: Neste artigo, objetivamos refletir sobre a discursivização da lusofonia como um projeto integrador da diversidade cultural e linguística dos países lusófonos, problematizando como o ensino de língua portuguesa promove um ensino decolonial (MIGNOLO, 2011). Na perspectiva integracionista (HARRIS, 1998), defendemos uma visão de linguagem integrada aos contextos de uso assumindo a língua como prática social e pensando na internacionalização da língua portuguesa num projeto plural e integracionista. No âmbito universitário brasileiro, apresentamos algumas ações institucionais promovidas pela Universidade da Integração Internacional da Lusofonia Afro-brasileira que contribuem para a construção de uma educação linguística integracionista. Igualmente, discutimos o ensino de língua portuguesa no cenário político-linguístico do curso de Letras dessa universidade na perspectiva de letramentos ideológico (STREET, 2014), antirracista (NASCIMENTO, 2019) e de resistência (SOUZA, 2011). Concluímos que ainda há um longo percurso para criação e manutenção de políticas públicas que assumam o compromisso com um Ensino Superior integracionista e democrático.

PALAVRAS-CHAVE: Integracionismo. Língua portuguesa. Ensino.

\footnotetext{
* Doutor em Linguística (UFSC), professor do Colegiado de Letras da Universidade da Integração Internacional da Lusofonia Afro-brasileira - UNILAB. E-mail: alexandre.silveira@unilab.edu.br.

** Doutora em Linguística (UFSC), professora colaboradora do Departamento de Estudos da Linguagem da Universidade Estadual de Ponta Grossa - UEPG. E-mail: charlott.eloize@gmail.com. 
RESUMEN: En este artículo, pretendemos reflexionar sobre la discursividad de la lusofonía como un proyecto que integra la diversidad cultural y lingüística de los países de habla portuguesa, discutiendo cómo la enseñanza de la lengua portuguesa promueve la enseñanza descolonial (MIGNOLO, 2011). Desde una perspectiva integracionista (HARRIS, 1998), defendemos una visión de la lengua integrada a los contextos de uso, asumiendo la lengua como práctica social y pensando en la internacionalización de la lengua portuguesa en un proyecto plural e integracionista. En el contexto universitario brasileño, presentamos algunas acciones institucionales impulsadas por la Universidad de Integración Internacional de la Lusofonía Afrobrasileña que contribuyen a la construcción de una educación lingüística integracionista. Asimismo, se discute la enseñanza de la lengua portuguesa en el escenario político-lingüístico de la carrera de Literatura de esta universidad desde la perspectiva de las alfabetizaciones ideológicas (STREET, 2014), antirracista (NASCIMENTO, 2019) y de resistencia (SOUZA, 2011). Concluimos que aún queda un largo camino por recorrer para la creación y mantenimiento de políticas públicas que asuman el compromiso con una Educación Superior integracionista y democrática.

PALABRAS-CLAVE: Integracionismo. Lengua Portuguesa. Enseñanza.

ABSTRACT: In this article, we aim to reflect on the discursiveness of Lusophony as a project that integrates the cultural and linguistic diversity of Portuguese-speaking countries, discussing how the teaching of Portuguese language promotes decolonial teaching (MIGNOLO, 2011). From an integrationist perspective (HARRIS, 1998), we defend a vision of language integrated to the contexts of use, assuming language as a social practice and thinking about the internationalization of the Portuguese language in a plural and integrationist project. In the Brazilian university context, we present some institutional actions promoted by the University of International Integration of Afro-Brazilian Lusophony that contribute to the construction of an integrationist linguistic education. Likewise, we discuss the teaching of Portuguese language in the political-linguistic scenario of the Literature course at this university from the perspective of ideological (STREET, 2014), anti-racist (NASCIMENTO, 2019) and resistance (SOUZA, 2011) literacies. We conclude that there is still a long way to go for the creation and maintenance of public policies that assume the commitment to an integrationist and democratic Higher Education.

KEYWORDS: Integrationism. Portuguese language. Teaching.

\section{INTRODUÇÃO}

A compreensão dos usos hibridizados de língua a partir dos efeitos da globalização, em que estão integradas pessoas e ambientes culturalmente distantes, indica um fenômeno linguístico mais dinâmico, que difere da perspectiva tradicional do monolinguismo tomado como norma. Diante da complexidade das práticas comunicativas em tempos contemporâneos e fluidos, este artigo tem em vista uma proposta de educação linguística integracionista (HARRIS, 1998).

Nosso enfoque é discutir o projeto político da lusofonia de uma maneira que problematize práticas segregacionistas de visão de língua. Ao tomarmos a língua como parte de um projeto político poderoso que reforça a classificação e a assimetria entre os sujeitos (MAKONI; SEVERO, 2015), propomos a problematização de categorias coloniais que inventaram os conceitos de raça e língua com finalidades segregacionistas. Dessa maneira, o multilinguismo e a diversidade cultural dos países de língua portuguesa devem ser debatidos de uma perspectiva integracionista, o que implica assumir um projeto decolonial problematizador de categorias cristalizadas e cristalizantes

No artigo, apresentamos o contexto de criação da Universidade da Integração Internacional da Lusofonia Afro-brasileira, seus objetivos e missão que apontam para uma estratégia de uma política educacional de internacionalização e para uma política linguística integracionista tendo como pretexto a lusofonia. Pensar nessa lusofonia criticamente também envolve uma reapropriação do seu aspecto "luso" e uma reconfiguração dos aspectos de sua "fonia", inclusive em termos decoloniais. Além disso, discutimos os grandes desafios sociais e políticos enfrentados na atualidade pela UNILAB, visto que recebemos estudantes de diferentes contextos culturais. 
Assim, em uma mesma sala de aula de um curso de licenciatura, por exemplo, há estudantes brasileiros quilombolas, indígenas, residentes em centros urbanos do interior da Bahia, ou de áreas rurais, além de pessoas advindas de outros estados do país. Há também estudantes guineenses provenientes de capitais de províncias e de tabancas (aldeias) mais distantes. Há igualmente angolanos, moçambicanos, são-tomenses, caboverdianos e timorenses. Nesse contexto multicultural, no Campus dos Malês, situado na cidade de São Francisco do Conde (BA), mais especificamente, no curso de Letras, dedicamo-nos a pensar a formação inicial de professores de língua portuguesa. Desse modo, esse idioma que une tantas identidades diferentes em uma única sala de aula, igualmente nos suscita reflexões críticas sobre ensino e cultura.

Ao longo do artigo procuramos debater acerca das consequências da herança colonial para o ensino do português a esses diferentes contextos, e discorrer acerca do fato de que um ensino de língua que considere a cultura dos estudantes pode ser um importante caminho a fim de se contribuir efetivamente com a ampliação das práticas de letramento - objetivo essencial da pedagogia culturalmente sensível.

\section{A INVENÇÃO E A ATUALIZAÇÃO DA LUSOFONIA}

A discursivização sobre o projeto de uma comunidade lusófona intensificou-se no período (pós)colonial, cujo marco foi a criação da Comunidade dos Países de Língua Portuguesa (CPLP), em 1996, em que o processo fundacional se baseou na partilha comum da língua e da cultura entre territórios que foram colônias de Portugal. Atualmente, o acordo político-diplomático está firmado entre Guiné-Bissau, Cabo Verde, São Tomé e Príncipe, Moçambique, Angola, Timor-Leste, Guiné-Equatorial, Brasil e Portugal (CPLP, 2021). Um dos grandes objetivos da CPLP é criar uma rede de cooperação internacional entre nações ditas lusófonas, ou seja, países que possuem a língua portuguesa como língua oficial.

A língua portuguesa parece ter funcionado como um instrumento para a reconstrução das "relações" entre os territórios que estiveram sob o domínio colonial português. Segundo Marchueta (2003), a lusofonia pretende reconstruir as relações entre os espaços e populações que estiveram sob domínio colonial de uma perspectiva moderna em que as ex-colônias se tornaram nações soberanas. A CPLP tornou-se um ator institucional relevante na mediação das relações internacionais lusófonas, com o pretexto da língua comum para promover intercâmbio de cooperação política, econômica e empresarial, constituindo-se como bloco político-econômico no cenário internacional. O caráter empresarial da CPLP nos últimos anos, especialmente após a inclusão da Guiné-Equatorial evidenciou interesses para além das questões linguísticas ou culturais - a saber, Brasil, Angola, Moçambique e Guiné Equatorial possuem potencial petrolífero -, o que tem contribuído para intensificar uma visão mercantil da língua. Isso faz com que, muitas vezes, as iniciativas em torno da difusão linguística operam mais segundo uma lógica da "economia linguística" do que da "Política Linguística" (LEVISKI, 2018).

No século XXI, em que a globalização é caracterizada por processos diaspóricos das mais diversas ordens - política, social, cultural, econômica e geopolítica (APPADURAI, 1996) -, torna-se uma tarefa complexa definir o que se entende por língua portuguesa (MOITA LOPES, 2013). Ancorados pela argumentação de Makoni e Meinhoff (2006) sobre a construção social e, portanto, discursiva das línguas, não podemos deixar de considerar que os projetos discursivos sobre a língua portuguesa são orientados por “ideologias linguísticas" (IRVINE; GAL, 2000). Deste modo, os saberes científicos sobre as línguas, bem como suas emergências em determinados contextos, são influenciados por modelos socioculturais, crenças, práticas sócio-históricas e visões de mundo.

Seguindo esse raciocínio, e tomando por base a perspectiva de que as línguas foram inventadas, como produtos de intervenção histórica e social (MAKONI; PENNYCOOK, 2007), postulamos que a língua portuguesa é uma invenção do dispositivo da lusofonia. A reboque da invenção das línguas, as categorias de raça e etnia também estiveram intrinsecamente envolvidas na invenção de povos e línguas durante o projeto colonial europeu (MAKONI; MEINHOF, 2006; MBEMBE, 2014). Além disso, importante trazer à tona a proposta de tradição inventada, de Hobsbawm (2015), a qual assevera que, na medida do possível, a língua é utilizada como legitimadora das ações e como coesão grupal, percebe-se um movimento de 'busca' - tomado como

Forum lingüístic., Florianópolis, v.19, Special Issue,p.7311-7323, Feb. 2022 
invenção - de referenciais culturais e linguísticos do passado a fim de legitimar a criação de uma Comunidade que compartilha um dado passado em língua portuguesa.

Neste sentido, a proposta que fazemos é pensar em lusofonia como um dispositivo (FOUCAULT, 2015) político gerencial da língua portuguesa composto de elementos linguísticos, culturais, identitários, econômicos e coloniais (LEVISKI, 2020). No funcionamento desse dispositivo, a língua portuguesa fez/faz parte de um projeto político que, por vezes, reforça a classificação e a assimetria entre os sujeitos (SEVERO; MAKONI, 2015). Sendo um dispositivo, a lusofonia opera (e é operada) em uma rede discursiva que perpassa por relações de poder e ideologias próprias dos contextos situacionais como o colonialismo, o neocolonialismo e os discursos operantes da globalização.

Sob uma visão decolonial (MIGNOLO, 2011), convém problematizar as relações de poder que envolvem as práticas e os discursos que operam na invenção de categorias como supranacional, transnacional e global para a língua portuguesa que recaem sobre um necessário debate acadêmico e político sobre o ensino da língua portuguesa. Neste debate, estão envolvidas questões interculturais, políticas e linguísticas, em que se deve considerar: i. as variedades do português no mundo, além do português brasileiro (PB) e do português europeu (PE), como o português moçambicano (NGUNGA, 2012; BALSALOBRE, 2017; TIMBANE, 2017; GONÇALVEZ, 2012), o português angolano (BERNARDO, 2017; NZAU, 2011; MINGAS, 2007; MIGUEL, 2014, ADRIANO, 2015), e assim em diante; ii. as sociedades africanas multilíngues de tradição oral (FARDON; FURNIS, 1994), em que o português recebe o estatuto de oficial e as línguas africanas são denominadas de “autóctones” e/ou nacionais.

Ao colocar, então, em relação tais considerações, podemos evidenciar tensões que, às vezes, tendem a favorecer as políticas institucionalizadas em detrimento das demandas e das realidades linguísticas locais. Consideramos que tais conflitos devem ser levados em conta na análise do que se entende por língua portuguesa como língua de escolarização. Embora exista o empenho da CPLP e dos governos brasileiro e português - especialmente por parte de intelectuais engajados com as questões linguísticas - no reconhecimento de um pluricentrismo da língua portuguesa, as políticas oficiais de difusão da língua portuguesa estão muitas vezes dissonantes das políticas promovidas pelos Estados e por práticas linguísticas locais.

Dentro desse complexo jogo, os Países Africanos de Língua Oficial Portuguesa (PALOP), por se tratar de contextos multilíngues e multiculturais, talvez tenham enfrentado insucesso devido à cópia de modelos de ensino estrangeiros, sem repensar a realidade local (TIMBANE, 2017; BALSALOBRE, 2017). Podemos pensar que são sociedades que estão em processo de (re)construção da língua portuguesa, que se distancia, paulatinamente, da variedade europeia e apresenta características linguísticas próprias em nível fonético-fonológico, sintático, semântico, lexical e pragmático. Uma insistência na preservação de modelos descontextualizados de usos linguísticos pode, por exemplo, agir de forma desagregadora, ou desintegradora, justamente por não atender satisfatoriamente às necessidades culturais e identitárias dos povos usuários. A língua portuguesa praticada em contextos multilíngues e multiculturais precisa, para fazer parte do repertório linguístico desses locais, assumir as peculiaridades de cada contexto, em consonância com o que vamos discutir sobre integracionismo linguístico na próxima seção desse texto.

Segundo Ofelia Garcia (2009), a educação no século XXI precisa assumir a tarefa de ensino multilíngue no sentido de investigar as práticas heterogêneas que integram o contexto de ensino/aprendizagem. A escolarização, em diálogos com concepções locais de educação e com apoio governamental, pode ajudar a reconhecer os significados que os sujeitos atribuem localmente às suas línguas. As práticas comunicativas precisam ser investigadas, ao invés de assumidas (BLOMMAERT; RAMPTON, 2011). Esse mergulho nas realidades locais dos usos linguísticos traz efetivas contribuições para o entendimento das adaptações pelas quais as línguas passam no cumprimento de seu papel cultural, identitário e comunicativo de cada grupo de indivíduos e, no caso da língua portuguesa em contextos multilíngues, contribui significativamente para a desconstrução de hierarquias e preconceitos linguísticos decorrentes da lógica colonial de valorização de uma única língua: a do colonizador.

Para pensarmos em uma internacionalização da língua portuguesa é preciso discutir, de forma paralela e conjunta, em uma política linguística de reconhecimento e valorização das línguas locais, fazendo com que o multilinguismo não seja encarado como 
problema. Igualmente, uma política linguística que considera práticas comunicativas locais também enfrentará as questões relativas ao ensino das línguas africanas. Makoni e Meinhof (2006, p. 200), nessa perspectiva, defendem que "[...] línguas africanas não necessariamente têm de ser padronizadas para ser ensináveis”, o que significa que a representação gráfica de uma língua não deve ser condição para que ela possa ser praticada, valorizada e reconhecida. Tudo isso converge para a organização de políticas de ensino linguístico que levem em consideração as práticas e necessidades linguísticas locais, atreladas aos projetos nacionais e internacionais de cada contexto, observando que a realidade cultural local não pode ser assolada por um projeto estatal. Antes, a valorização das realidades locais deve conduzir as políticas de ensino linguístico dentro de uma pedagogia culturalmente sensível, conforme abordaremos na terceira seção desse texto.

A implementação de políticas de ensino de português, portanto, deveria levar em consideração as assimetrias das complexidades linguísticas, políticas, culturais e coloniais para se estabelecer como uma proposta de emancipação para o povo a que se destina. Pensando na realidade brasileira, propomos colocar em relação tais tensões e hibridizações da língua para repensar sobre as práticas de ensino na universidade brasileira, com objetivo de construir um projeto plural e integracionista de ensino. Nesse sentido, na sequência, discutimos a criação da UNILAB, em que 50\% das vagas são reservadas aos alunos da "África Lusófona" e do Timor-Leste.

\section{POR UMA EDUCAÇÃO LINGUÍSTICA INTEGRACIONISTA: UM OLHAR PARA A UNILAB}

É importante ressaltar que uma abordagem integracionista da linguagem se opõe a uma linguística tradicional - em grande medida alimentada pela lógica colonial abordada na seção anterior - pautada numa forma muito limitada relativa ao que é entendido por "língua". Uma limitação que descola o objeto língua de suas práticas de produção ocorrentes no cotidiano das pessoas, com suas singularidades, identidades e culturas. Dado que, de acordo com Calvet (2007, p. 12), "[...] as línguas não existem sem as pessoas que as falam, e a história de uma língua é a história de seus falantes”, desconsiderar as práticas linguísticas do cotidiano é desconsiderar o universo - real e simbólico - em que as pessoas interagem. Em suma, pensar a língua numa perspectiva integracionista é um contraponto à promoção de uma visão (e de discursos) sobre a língua que funcionam como agentes segregacionistas na sociedade.

Roy Harris (1998, p. 1) afirma que "[...] o principal objetivo da linguística integracionista é mudar o modo como as pessoas pensam a linguagem", algo que, na visão do autor, é foco de muitas questões políticas, culturais e identitárias, participando ativamente das "[...] relações [dos indivíduos] com outros membros do que eles chamam sua comunidade ou comunidades." (HARRIS, 1998, p. 4). Nesse enquadramento, a língua é vista como parte integrante dos contextos em que é utilizada, praticada e produzida, não havendo como desconectá-la dessas questões que são cruciais na produção de significados e saberes constituídos. Consequentemente, seguindo o raciocínio de Roy Harris, uma postura analítica que desconsidere essas questões provoca uma série de problemas como: o entendimento enviesado do conteúdo da linguagem e de seus usuários e a produção daquilo que o autor chama de "ficções convenientes" para a sala de aula, dentre outros resquícios do pensamento colonial. Em outras palavras, estes são exemplos de práticas desagregadoras, como mencionado na seção anterior, ou segregacionistas, a partir do entendimento distorcido da língua e dos sujeitos que a utilizam.

Persistem, em variados espaços sociais, discursos que segregam a partir dessa miopia linguística e que muito tem contribuído para ações discriminatórias de toda sorte como a misoginia, o racismo, a xenofobia, dentre outras. Trata-se, na verdade e infelizmente, de práticas bem comuns, que ocorrem dentro e fora dos ambientes formais de educação. Podemos citar aqui, por exemplo, a marcação com aspas destacando formas linguísticas cotidianas que não obedecem à chamada "norma culta", como na fala de um entrevistado em um programa de televisão que teve sua fala legendada e marcada da seguinte forma: “Eles pediram 'pra mim' deitar no chão e fechar os olhos [...]" (BAHIA MEIO DIA, 2021). Também encontramos a segregação linguística respaldada por normas da escrita acadêmica que prevê o uso da expressão sic, que significa "desse jeito" em latim, quando se quer destacar os desvios da norma culta praticados em falas transcritas nos textos acadêmicos. Mais recentemente, também ocorreu o caso da

Forum lingüístic., Florianópolis, v.19, Special Issue,p.7311-7323, Feb. 2022 
jornalista Cecília Flesch, do canal fechado GloboNews, que publicou um comentário pejorativo a respeito da fala do ex-presidente Lula por ter pronunciado "adevogado", em vez de "advogado". Isso sem contar todo o aparato crítico sem fundamento que foi mobilizado pela direita conservadora e pela grande mídia contra Dilma Rousseff por conta da forma "presidenta" utilizada por ela e por seu governo nas comunicações oficiais.

A perspectiva integracionista da linguagem traz à tona a necessidade de se buscar, através de orientações teórico-metodológicas includentes e anti-hegemônicas formas de entendimentos linguísticos mais condizentes com a diversidade e com a dignidade humanas. Que abandonem o mito do monolinguismo brasileiro (OLIVEIRA, 2009; BORTONI-RICARDO, 1984; CAVALCANTI, 2000) respeitando as mais de 200 línguas indígenas brasileiras, os falantes de LIBRAS como primeira língua, as línguas de herança, os imigrantes em situação de refúgio e a diversidade própria da variante nacional da língua portuguesa.

Para além dessas questões, é importante pensar numa visão integracionista relativamente às políticas linguísticas para a internacionalização do ensino superior brasileiro, o que significa repensar a forma como são organizados os testes linguísticos praticados, os exames de proficiência linguística, como o CELPE-BRAS, e as avaliações linguísticas feitas em concursos variados que descartam/desvalorizam variantes endógenas e exógenas da língua portuguesa brasileira. Trata-se de práticas que impõem sanções a diversas pessoas em prol de uma postura política excludente pautada em visões limitadas do que vem a ser "língua". Trata-se ainda de buscar mecanismos que não façam da "língua" um fator de exclusão, mas antes da "diversidade linguística" um pretexto para a inclusão e integração social.

Defende-se aqui a construção de uma educação linguística que abarque o papel sociopolítico da linguagem, considerando os atravessamentos coloniais vivenciados e as imposições de um imperialismo linguístico contemporâneo, que sempre atinge incisivamente os falares subalternizados envolvendo as questões de gênero, classe e raça. Essa educação linguística, totalmente em consonância com uma perspectiva integracionista da linguagem, atua na contramão da manutenção de epistemologias eurocentradas ou brasilcentradas de uma falta de vontade em buscar entendimentos contrários ao linguicídio (NASCIMENTO, 2019) promovido historicamente no Brasil.

Diante do exposto, passamos a olhar para uma política pública brasileira que, em alguma medida, busca atender a essas questões tratadas até aqui. A Universidade da Integração Internacional da Lusofonia Afro-brasileira - UNILAB - consiste num projeto de reparação histórica quanto às questões raciais tendo sido criada pelo governo do então presidente Lula, a partir dos trabalhos de uma comissão técnica instituída em 2008 que, para além das questões próprias relativas à implantação de uma nova universidade, também estudou

[...] propostas e diretrizes elaboradas por entidades vinculadas ao desenvolvimento da educação superior no mundo, privilegiando temas propícios ao intercâmbio de conhecimentos na perspectiva da cooperação solidária, além de sua aderência às demandas nacionais, relevância e impacto em políticas de desenvolvimento econômico e social. (UNILAB, 2018)

A partir de 20 de julho de 2010, portanto, o presidente Lula sancionou a Lei ${ }^{\circ} 12.289$, instituindo a UNILAB como Universidade Pública Federal que hoje, 11 anos depois, possui quase a totalidade de seus estudantes negros, negras e negres, a grande maioria de baixa renda, oriundos de zonas rurais e comunidades remanescentes de quilombos. Há um grupo considerável de estudantes pertencentes à comunidade LGBTQIA+. Compõem também o corpo discente cerca de 30\% a 40\% de estudantes estrangeiros oriundos da Guiné-Bissau, de Angola, Moçambique, Cabo-Verde, São Tomé e Príncipe e Timor-Leste. Há também estudantes participantes do Programa de Estudantes de Convênio de Graduação (PEC-G) vindos de Gana, Togo e da Guiné Equatorial. A sede da UNILAB encontra-se na cidade de Redenção, no Ceará, primeira cidade a considerar livres os negros e negras escravizados no Brasil. No Ceará, há ainda os campi de Palmares e Auroras. No estado da Bahia, mais precisamente na cidade de São Francisco do Conde, no Recôncavo Baiano, há o Campus dos Malês. 
Diante desse panorama estudantil que a UNILAB possui, cuja diversidade cultural e linguística é grande, é pertinente trazer à tona a seguinte reflexão: "A UNILAB promove um integracionismo linguístico?" O conceito de "Integração", que aparece no nome da universidade, possui, em alguma medida, uma preocupação com um integracionismo da(s) linguagem(ns) que convivem no ambiente unilabiano?" Essas e outras questões, nada simples, ainda que necessárias, precisam ser abordadas do ponto de vista do(s) currículo(s), das dinâmicas socioculturais e das políticas institucionais existentes na universidade.

Na dimensão curricular, talvez uma das possibilidades mais marcantes desse integracionismo resida na organização do curso de Bacharelado Interdisciplinar em Humanidades (BIH), um curso de três anos de duração em que, a partir do segundo ano, os/as estudantes escolhem a segunda graduação que pretendem concluir dentre as seguintes possibilidades: licenciaturas em História, Pedagogia, Ciências Sociais ou Bacharelado em Relações Internacionais. Isso significa dizer que, em cinco anos, os estudantes podem concluir dois cursos de graduação, dentro de uma perspectiva menos eurocentrada e que traz questões fundamentais para discussão em suas trajetórias formativas, como o colonialismo, o racismo e a educação antirracista, os direitos humanos e a igualdade social, dentre outros. Na proposta formativa de BIH, há uma flexibilização da trajetória curricular escolhida pelos/as estudantes no sentido de garantir-lhes certa autonomia quanto à sua formação dentro de estudos e temáticas que escolham aprofundar.

É importante destacar também alguns componentes curriculares do chamado "núcleo comum" a todos os cursos, que cumprem também um papel de integradores das diversas realidades sociais e culturais existentes na UNILAB, como "Sociedades, Diferenças e Direitos Humanos nos Espaços Lusófonos". No universo do Curso de Letras, é possível destacar os estudos de literatura africana e afro-brasileira e os componentes curriculares "Estudo de línguas crioulas" e componente "Políticas e Planejamento Linguístico", ambos componentes obrigatórios do curso. Isso sem contar os estudos de letramentos de (re) existência (SOUZA, 2011) e letramentos políticos (SILVEIRA, 2020) e antirracistas que permeiam diversas discussões promovidas sobretudo nas práticas de estágio supervisionado.

Quanto à dimensão sociocultural, a presença de alunos/as e professores/as de variados contextos nacionais e estrangeiros, por si só, fomenta conversas e práticas interculturais, nos ambientes formais e informais da universidade. Essa diversidade enriquece debates e estudos, amplia o repertório sociopolítico e contribui significativamente para a formação inicial e continuada de todes. $\mathrm{O}$ acontecimento de uma aula corriqueira ganha um incremento diverso e multicultural, proporcionando estudos comparados e aprendizados que nem sempre são planejados pelos/as docentes em seus planejamentos.

Em termos de ações institucionais, para além de políticas afirmativas e do trabalho do setor de assistência estudantil, há na UNILAB o "Programa Pulsar" que seleciona semestralmente estudantes bolsistas para realizarem o acolhimento acadêmico de estudantes ingressantes. O Pulsar promove rodas de conversas, minicursos, atendimentos individualizados no sentido de facilitar o processo de inserção universitária dos/das recém-chegados/as. Também se destaca o "Festival das Culturas", evento realizado anualmente, cujo objetivo principal consiste na confraternização e convívio das manifestações culturais em sua diversidade unilabiana. O evento tem impacto regional, envolvendo as comunidades de São Francisco do Conde, onde está o Campus dos Malês, e das cidades de Candeias, Santo Amaro da Purificação e Madre de Deus. Isso sem contar os inúmeros projetos de extensão existentes e uma prática calorosa de um certo "Aquilombamento", que fortalece essa resistência necessária com relação às práticas segregacionistas.

Certamente, há inúmeras questões de ordem individual, institucional e estrutural que fazem com que a UNILAB tenha ainda um caminho a percorrer no sentido de ser considerada como instituição modelo em termos de promoção de uma educação linguística integracionista. Contribuem para essa afirmação diversas razões que vão desde o processo de desconstrução colonial das mentalidades individuais, até uma vontade política institucional mais assertiva em prol desse integracionismo que está sendo discutido ao longo do texto. A UNILAB, seguindo orientações do governo federal, precisa avançar em termos de construir políticas públicas que venham a assumir, de fato, o compromisso com o Ensino Superior promotor de uma educação linguística integracionista e democrática, que combata veementemente os mecanismos segregatórios ainda vigentes.

Forum lingüístic., Florianópolis, v.19, Special Issue,p.7311-7323, Feb. 2022 


\section{POR QUAL ENSINO DE LÍNGUA PORTUGUESA?}

Conforme debatido, a discursivização da lusofonia como um projeto integrador, sem estar associado a políticas linguísticas críticas, as quais legitimem a diversidade cultural e linguística dos países cuja língua oficial é a portuguesa, tem se consolidado como uma herança colonial que perpetua uma visão de mundo eurocêntrica e limitadora. Nesse sentido, com vistas a um projeto decolonial, aos profissionais da educação dos diferentes países que têm a língua portuguesa como língua de escolarização, é necessário questionar: qual é o ensino de língua portuguesa que efetivamente desejamos?

Ao se considerar o cenário político brasileiro, é possível observar que, fundamentalmente, até o período da ditadura militar no Brasil, era estimulado que o ensino de língua portuguesa ocorresse de forma acrítica. Amplamente baseado em metodologias behavioristas/comportamentais, o foco do ensino de língua portuguesa recaía em memorização da nomenclatura gramatical e na aplicação de regras gramaticais a exercícios prototípicos que pouco contribuíam com a ampliação do repertório comunicativo dos estudantes. No mesmo sentido, as atividades de leitura e de produção de texto - quando havia - pautavam-se em questões superficiais, que pouco estimulavam processos ideológicos de letramento. Letramento ideológico é, pois, um conceito proposto por Brian Street (2014), segundo o qual, por meio do ensino de língua materna, o estudante tem a possibilidade de aprender "modelos culturais de identidade e personalidade, não apenas a decodificar a escrita ou escrever com determinada caligrafia" (STREET, 2014, p. 154). De acordo com o autor, se esse modelo de letramento não for privilegiado como política linguística, as consequências sociais podem ser irreversíveis: "Se esse é o caso, então, deixar o processo crítico para depois que eles tiverem aprendido vários dos gêneros letrados usados na sociedade é descartar, talvez para sempre, a socialização numa perspectiva crítica" (STREET, 2014, p. 154).

Após o fim da ditadura no Brasil, a partir de 1985, houve alguns marcos legais que estimularam uma visão de educação mais democrática. Nesse sentido, a Constituição Cidadã de 1988, a Lei de Diretrizes e Bases da Educação de 1996, a promulgação dos Parâmetros Curriculares Nacionais a partir de 1998, criaram condições para que se estimulasse um processo de educação linguística no país. Nessa mesma direção, é imperioso salientar que, pelo menos desde os anos 1970, as universidades públicas brasileiras analisavam a língua em uso no país e estimulavam a sua descrição, também em uma perspectiva crítica.

Entretanto, o ensino de língua portuguesa alicerçado em gêneros textuais, que estimula tanto a ampliação do repertório comunicativo dos estudantes, quanto processos de leitura e de produção textual mais reflexivos, não chegou a adentrar as salas de aula de todo o país. Ainda que seja necessário salientar uma série de esforços nessa direção - como a criação e expansão do PROFLETRAS, cujo público-alvo são docentes já atuantes na área de língua portuguesa no Ensino Fundamental, a partir de 2013 - efetivamente, os processos críticos de letramento continuam a ser negligenciados no cotidiano escolar. Justamente por isso, a crítica feita por Magda Soares, em Linguagem e escola: uma perspectiva social (2017 [1986]) continua válida:

Muitos são os fatores responsáveis por essa incompetência, mas parte significativa da responsabilidade deve ser atribuída a problemas de linguagem: o conflito entre a linguagem de uma escola histórica e socialmente criada para atender às camadas privilegiadas, cujos padrões linguísticos essa escola usa e quer ver usados, e a linguagem das camadas populares, que ela censura e estigmatiza, é uma das principais causas do fracasso dos alunos pertencentes a camadas populares, na aquisição do saber escolar. (SOARES, 2017, p. 10-11)

Contemporaneamente, o processo de consolidação democrática do Brasil encontra-se em suspenso. A partir da destituição da Presidenta da República em 2016, tem havido uma série de ameaças à universidade pública e à sua autonomia, a partir de projetos como o "Escola sem partido" e o "Future-se". Soma-se a isso, a promulgação da Base Nacional Comum Curricular (BNCC), em 2018 - a qual não contou com um amplo debate democrático - e a implementação da Base Nacional Comum para a Formação de Professores da Educação Básica (BNC). Fundamentalmente, atribui-se às dificuldades dos processos de ensino aprendizagem brasileiros aos profissionais de educação, silenciando o desmonte sistêmico da educação a que estamos assistindo, com cortes de verbas e de investimentos, e proposições advindas de agentes privados dentro do MEC. 
Diante desse cenário pouco animador, como os cursos de licenciatura têm se colocado? Particularmente, como os cursos de Letras, os quais formam profissionais da área de língua portuguesa, têm se posicionado? Ao entendermos a gravidade da conjuntura política atual como um alerta - agravada pela pandemia de covid-19 - é essencial que os cursos de Letras observem seus projetos: quais professores(as) estamos formando? Eles/elas estão sendo formados para qual realidade social? Formamos docentes para a educação básica? Para qual educação básica?

Conforme anteriormente expresso, a UNILAB tem se mostrado uma universidade pública federal de vanguarda, em função de sua vocação multicultural. Nesse sentido, o seu projeto político pedagógico mira simultaneamente na interiorização e na internacionalização, de tal forma que, em uma mesma sala de aula de um curso de licenciatura, por exemplo, há estudantes brasileiros(as) quilombolas, indígenas, residentes em centros urbanos do interior da Bahia, ou de áreas rurais, além de pessoas advindas de outros estados do país. Há, nessa mesma sala, também estudantes guineenses provenientes de capitais de províncias e de tabancas (aldeias) mais distantes. Há igualmente angolanos(as), moçambicanos(as), são-tomenses, caboverdianos(as), timorenses. Assim sendo, se a língua portuguesa é um denominador comum a esses e a essas estudantes, de igual sorte, as idiossincrasias de cada um dos povos ali representados constituem-se elementos integradores, a fim de que essa língua portuguesa seja constantemente repensada e as suas variedades linguísticas legitimadas.

Particularmente, o curso de Letras da UNILAB (Campus dos Malês) conta com uma proposta pedagógica decolonial. Assim sendo, nos componentes curriculares de práticas de estágio supervisionado - especialmente em Práticas de Estágio 02: alfabetização e letramento nos espaços lusófonos - temos empreendido coletivamente reflexões sobre propostas de letramentos antirracistas (NASCIMENTO, 2019) e de letramentos de resistência (SOUZA, 2011); sobre os multiletramentos (ROJO; MOURA, 2012); sobre estratégias de ampliação do repertório linguístico crítico dos estudantes (ZILLES; FARACO, 2015; SCHNEUWLY; DOLZ, 2004). Ademais, aos debates desse componente curricular, são imprescindíveis as contribuições suscitadas pela pedagogia balanta (NAMONE, 2020), pela pedagogia das comunidades quilombolas, pela pedagogia das comunidades indígenas.

No contexto multicultural visto em uma sala de aula da UNILAB, dentre muitas reflexões pedagógicas essenciais, o sentido de "lusofonia" precisa ser continuamente avaliado. Assim sendo, debatemos que em países multilíngues, particularmente, em contextos em que a língua portuguesa não é língua materna, os processos de ampliação de letramentos necessariamente devem valorizar as línguas étnicas, bem como as suas variedades linguísticas e culturais, de tal modo que o ensino de língua portuguesa ocorra em função do que efetivamente é: língua segunda, ou terceira, ou quarta, a depender do contexto. Analogamente, mesmo dentre falantes da língua portuguesa, o sentido de homogeneização linguística precisa ser continuamente combatido, uma vez que as diferentes normas linguísticas encontram contextos sociais específicos de uso e, portanto, todas são igualmente legítimas e devem ter garantidos os seus espaços de escolarização.

Em suma, alicerçados em um modelo de Pedagogia culturalmente sensível (BORTONI-RICARDO, 2004, 2005; CYRANKA, 2015, 2018), segundo a qual professores(as) sensíveis à variedade linguística e cultural de seus/suas estudantes criam em sala de aula um ambiente de aprendizado em que todos e todas têm suas vozes reconhecidas e legitimadas, entendemos ser possível a formação inicial docente a partir de uma perspectiva crítica e decolonial. Portanto, à pergunta "Por qual ensino de língua portuguesa?", acreditamos que um ensino avessamente proporcional a práticas de silenciamento e à manutenção de grupos historicamente hegemônicos nos países que têm a língua portuguesa como essencial é um possível caminho. Nesse sentido, para além dos enfrentamentos políticos empreendidos por toda a sociedade na direção de lutas democráticas, os cursos de formação de professores(as) têm um importante papel a desempenhar, a fim de contribuir efetivamente com a ampliação das práticas de letramento críticas das futuras gerações. 


\section{CONSIDERAÇÕES FINAIS}

A abordagem integracionista nos estudos da linguagem, como discutimos nesse estudo, propõe uma educação linguística que lide com as questões das diversidades linguísticas de forma includente e respeitosa às práticas multilíngues. Nessa perspectiva, o mito do monolinguismo tomado como norma configura-se como ato segregacionista, interferindo negativamente - e por vezes, violentamente - nas existências e identidades linguísticas que convivem socialmente. O grande desafio imposto à linguística, como ciência, e às práticas educativas encontra-se em, tomando a diversidade por norma, integrar saberes e culturas em uma formação crítica, democrática e equânime.

Discutimos a lusofonia como um projeto político que mais segrega que acolhe, dentro do qual discursos e práticas coloniais reforçam abismos sociais e distribuem privilégios a partir de uma hierarquização social construída em torno da língua, portuguesa, no caso. No entanto, trouxemos à tona, a partir do caso da UNILAB, a construção repaginada da lusofonia numa perspectiva crítica e decolonial que abarca a diversidade linguística existente no seio da comunidade de falantes da língua portuguesa, destacando as riquezas e as potencialidades que um comprometimento com a descentralização linguística do poder pode proporcionar. Evidentemente, diante das lógicas coloniais ainda cristalizadas nas mentes e dinâmicas sociais, consistem em grandes desafios e, por vezes, entraves, para ações mais amplas e significativas nesse sentido, o que nos convida a repensar o conceito de língua, de ensino de língua e o papel da universidade quanto a essa questão. Por que ensinar língua? Para quê?

Diante dessas complexidades, emerge a capital importância dos indivíduos e suas culturas, de suas identidades e projetos de vida, de suas necessidades e anseios, de sua múltipla forma de "ser", "estar" e "conviver" na sociedade. Não se trata apenas de discutir os objetivos da educação linguística para que a diversidade "caiba" nos espaços sociais de interação humana, mas, talvez, recriar esses espaços a partir de um trabalho engajado em termos de letramentos anti-hegemônicos que desfaçam as construções sócio discursivas que historicamente discriminaram, segregaram, desrespeitaram e fomentaram as exclusões em termos de raça, gênero, credo, classe, aparência física e língua. Trata-se, portanto, de um compromisso da agenda política governamental, científica, acadêmica e, mais especificamente, linguística, em prol de um integracionismo linguístico efetivo.

\section{REFERÊNCIAS}

ADRIANO, P. S. A crise normativa do português em Angola: clitização e regência verbal: que atitude normativa para o professor e revisor? Luanda: Mayamba, 2015.

APPADURAI, A. Modernity at Large. Minneapolis: University of Monnesota Press, 1996.

BALSALOBRE, S. R. G. Expressões de poder e de solidariedade em Moçambique e em Angola: observando a inter-relação entre gênero e formas de tratamento. RILP -Revista Internacional em Língua Portuguesa, n. 32, p. 53-78, 2017. Disponível em: https://www.rilp-aulp.org/index.php/rilp/article/view/RILP2017.32.3. Acesso em: 26 jan. 2022.

BERNARDO, E. P. J. Norma e variação linguística: implicações no ensino da língua portuguesa em Angola. RILP - Revista Internacional em Lingua Portuguesa, n. 32, p. 37-52, 2017. Disponível em: https://doi.org/10.31492/21842043.RILP2017.32/pp.39-54. Acesso em: 26 jan. 2022.

BLOMMAERT, J.; RAMPTON, B. Language and Superdiversity. Diversities, v.13, n.2, p. 1-21, 2011.

BORTONI-RICARDO, S. M. Educação em língua materna: a sociolinguística em sala de aula. São Paulo: Parábola, 2004. 
BORTONI-RICARDO, S. M. Nós cheguemu na escola, e agora? Sociolinguística e educação. São Paulo: Parábola, 2005.

BRASIL. Ministério da Educação e do Desporto. Lei n 9.394, de 20 de dezembro de 1996. Estabelece as diretrizes e bases da educação nacional. Diário Oficial da União, Brasília, DF, 23 dez. 1996. Disponível em: http://www.planalto.gov.br/ccivil 03/Leis/L9394.thm. Acesso em: 26 jan. 2022.

BRASIL. Secretaria de Educação Fundamental. Parâmetros curriculares nacionais. Brasília: MEC; SEF, 1997.

CALVET, L. J. As políticas linguísticas. Trad. Izabel de Oliveira Duarte, Jonas Tenfen e Marcos Bagno. São Paulo: Parábola, 2007.

CPLP. Estados-membros (2021). Disponível em: http://www.cplp.org/id-2597.aspx. Acesso em: 21 jun. 2021.

CYRANKA, L. A pedagogia da variação linguística é possível?. In: ZILLES, A. M. S.; FARACO, C. A. (org.). Pedagogia da variação linguística: língua, diversidade e ensino. São Paulo: Parábola, 2015. p. 31-51.

CYRANKA, L. M.; BARROSO, T. (org.). A pedagogia da variação linguística na escola: experiências bem sucedidas. Londrina: EDUEL, 2018.

FARDON, R.; FURNISS, G. African languages, development and the state. London: Routledge, 1994.

FOUCAUlT, M. Genealogia e poder. In: FOUCAUlT, M. Microfísica do poder. Tradução de Roberto Machado. 3. ed. Rio de Janeiro: Paz e Terra, 2015. p. 262 - 277.

GARCIA, O. Bilingual education in the 21 st century: A global perspective. Malden/ Oxford: Wiley/ Blackwell, 2009.

GONÇALVEZ, P. Lusofonia em Moçambique: com ou sem glotofagia? 2012. Comunicação pessoal. Disponível em: 313http://www.catedraportugues.uem.mz/lib/docs/lusofonia_em_mocambique. Acesso em: 2 abr. 2020.

IRVINE J. T; GAL, S. Language ideology and linguistic differentiation. In: KROSKRITY, P. V. (org.). Regimes of Language: Ideologies, polities, and identities. Santa Fe: School of American Research Press, 2000. p. 35-84.

HARRIS, R. Integrational linguistics In: VERSCHUEREN; OSTMAN; BLOMMAERT; BULCAEN (ed.). Handbook of Pragmatics. Amsterdam: John Benjamins, 1998. p. 1-18.

HOBSBAWM, E. Introdução: a invenção das tradições. In: HOBSBAWM, E.; RANGER, T. (org.). A invenção das tradições. Tradução de Celina Cardim Cavalcante. 10. ed. São Paulo: Paz e Terra, 2015. p. 7-24.

LEVISKI, C. E. O governo da língua: implicações do conceito de gestão na política linguística. Revista da Abralin, v. 17, n. 2, p. 294 332, $2018 . \quad$ Disponível em: https://revista.abralin.org/index.php/abralin/article/view/485\#: :text=O\%20governo\%20da\%20l\%C3\%ADngua\%20segue,linguist a\%20no\%20papel\%20de\%20especialista. Acesso em: 26 jan. 2022.

LEVISKI, C. E. A lusofonia como dispositivo: uma proposta analítica. In: VASCONCELOS, S. I. C. C. de; SOUZA, F. M. de (org.). Lusofonias em debate. São Paulo: Mentes Abertas, 2020. p. 25-45.

MAKONI, S.; MEINHOF, U. Linguística aplicada na África: desconstruindo a noção de "língua". In: MOITA LOPES, L. P da (org.). Por uma linguística aplicada indisciplinar. São Paulo: Parábola Editorial, 2006. p. 191-213. 
MAKONI, S.; PENNYCOOK, A. Disinventing and Reconstituting Languages. Clevedon: Multilingual Matters, 2007.

MARCHUETA, M. R. A CPLP e seu enquadramento. Portugal: Ministério dos Negócios Estrangeiros, 2003.

MBEMBE, A. Crítica da razão negra. Trad. Marta Lança. Portugal: Antígona, 2014.

MIGNOLO, W. The Darker Side of Western Modernity: Global Futures, Decolonial Options. Durham: Duke UP, 2011.

MIGUEL, M. H. Dinâmica da pronominalização no português de Luanda. Luanda: Mayamba, 2014.

MOITA LOPES, L. P. (org.). Português no século XXI: cenário geopolítico e sociolinguístico. São Paulo: Parábola, 2013.

NAMONE, D. Consequências da língua portuguesa na trajetória escolar dos estudantes na Guiné-Bissau: caso dos alunos do ensino básico da etnia Balanta Nhacra na região de Tombali. 2020. Tese (Doutorado em Ciências Sociais) - Faculdade de Ciências e Letras, UNESP. Araraquara/SP, 2020. Disponível em: https://repositorio.unesp.br/handle/11449/194202. Acesso em: 25 jun. 2021.

NASCIMENTO, G. Racismo linguístico: os subterrâneos da linguagem e do racismo. Belo Horizonte: Letramento, 2019.

NGUNGA, A. Interferências de línguas moçambicanas em português falado em Moçambique. Revista Científica da Universidade Eduardo Mondlane. v. 1, n. 0, p. 7-20, 2012.

NZAU, D. G. N. A língua portuguesa em Angola: um contributo para o estudo da sua nacionalização. 2011. 203f. Tese. (Doutorado em Letras), Departamento de Letras, Universidade de Beira Interior, Covilhã, 2011.

OLIVEIRA, G. M. Brasileiro fala português: Monolinguismo e Preconceito Linguístico. Revista Linguasagem, n.11, p. 1-9, novdez, 2009.

ROJO, R.; MOURA, E. (org.). Multiletramentos na escola. São Paulo: Parábola, 2012.

SCHNEUWLY, B.; DOLZ, J. Gêneros orais e escritos na escola. Trad. e org. Roxane H. R. Rojo e Glaís S. Cordeiro. Campinas, SP: Mercado de Letras, 2004.

SEVERO, C. G.; MAKONI, S. B. Políticas linguísticas Brasil-África: Por uma perspectiva crítica. Florianópolis: Insular, 2015.

SILVEIRA, A. C. Letramento político: por uma educação linguística democrática. Travessias Interativas. v. 10, n. 22, p. 53-66, jul.dez., 2020. Disponível em: https://seer.ufs.br/index.php/Travessias/article/view/15316. Acesso em: 26 jan. 2022.

SOARES, M. Linguagem e escola: uma perspectiva social. São Paulo: Contexto, 2017.

SOUZA, A. L. S. Letramento da reexistência: Poesia, grafite, música, dança, hip-hop. São Paulo: Parábola, 2011. 
STREET, Brian V. Letramentos sociais: abordagens críticas do letramento no desenvolvimento, na etnografia e na educação. Trad. Marcos Bagno. São Paulo: Parábola, 2014.

TIMBANE, A. A variação linguística do português moçambicano: uma análise sociolinguística da variedade em uso. RILP Revista Internacional em Língua Portuguesa, n. 32, p. 17-36, 2017. Disponível em: https://doi.org/10.31492/21842043.RILP2017.32/pp.19-38. Acesso em: 26 jan. 2022.

UNILAB. Sobre a Unilab. Site Institucional. Disponível em: https://unilab.edu.br/sobre-a-unilab/ Acesso em: 27 jul. 2021.

\section{(ㄷ) (1) $(3)$}

Recebido em 31/07/2021. Aceito em 10/01/2022. 